\title{
FROM BAUHAUS TO DESIGN THINKING AND BEYOND: A COMPARISON OF TWO DESIGN EDUCATIONAL SCHOOLS
}

\author{
K. Thoring ${ }^{1,2, 凶}$, R. M. Mueller ${ }^{3,4}$, S. Giegler ${ }^{1}$ and P. Badke-Schaub ${ }^{2}$ \\ ${ }^{1}$ Anhalt University of Applied Sciences, Germany, ${ }^{2}$ Delft University of Technology, The Netherlands, ${ }^{3}$ Berlin \\ School of Economics and Law, Germany, ${ }^{4}$ University of Twente, The Netherlands \\ $\bigotimes$ katja@thoring.com
}

\begin{abstract}
This paper compares two pioneering design educational approaches: the historic Bauhaus school founded in 1919 in Germany, and contemporary design thinking education, based on the example of the "HPI School of Design Thinking". We compare both approaches according to six emerging categories: (1) curriculum, (2) multi-disciplinarity, (3) mind-set and culture, (4) study environment, (5) conditions for innovation, and (6) socio-economic context. We outline differences and similarities and discuss the possible impact for future design education.
\end{abstract}

Keywords: design thinking, design education, design learning, Bauhaus

\section{Introduction}

Design education, today, is in flux. While the craftmanship of formal aesthetics, such as the choice and assembly of shapes, colours, materials, and textures, is still one of the core skills that need to be trained at design school, also complex problem-solving, the design of intangible services, and identify user needs have become part of a designer's typical tasks. The designer's field of work has even expanded towards rather non-design-related fields, such as politics, government, or finance (Dorst, 2015; Junginger, 2013). We argue that this wide scope of designerly activities can be traced back to two influential streams of design education: (1) the Bauhaus movement (1919-1933) and (2) today's design thinking process.

Although almost a century lies in between the two educational concepts, both can be considered radical and innovative for their respective times. Many authors traced the roots of design thinking back to the Bauhaus (Chen and He, 2013; Donoso et al., 2018; Findeli, 2001; Orlandi, 2010; Vogel, 2009) but none of them offered a methodical comparison of the two approaches that outlines the main differences and similarities. Such a reflected analysis shall be conducted in this paper, which leads to the following research questions:

RQ1: What differences and similarities can be identified in contemporary design thinking education and the historic Bauhaus school?

$R Q 2:$ What can we learn from these insights about design education, today?

We argue that the work presented in this paper contributes to a better understanding of the various facets that constitute design education and helps to position design education in the socio-economical context of the current times. 


\section{Historical roots}

\subsection{Bauhaus}

In 2019, the 100th anniversary of the historic Bauhaus was celebrated in Germany and worldwide. In its early years, the avantgarde design school was both, praised and criticized for its radical and innovative design educational concepts. It can be argued that the Bauhaus era marked the starting point of the industrial design discipline, superseding the prior arts-and-crafts movement of the late 19th and early 20th century. The initial Weimar era (1919-1925) of the Bauhaus was characterized by the goal to 'synthesize the arts' and a strong focus on the teaching of craftsmanship (Wilhelm and Gropius, 1983, p. 12), and the goal to create a unity between art and technology, as proposed by Walter Gropius in 1923 (MacCarthy, 2019, p. 146). Later in Dessau (1925-1932), the focus of the Bauhaus shifted towards industrialization and mass production (Siebenbrodt and Schöbe, 2012, p. 30). After the closing of the institution in 1933, many of the former Bauhaus students and teachers emigrated to other countries (mostly to the USA) and spread the Bauhaus idea beyond the actual existence of the Bauhaus itself. As of today, many design schools are still following the Bauhausapproach (Chen and He, 2013; Findeli, 2001).

\subsection{Design thinking}

More recently, design thinking has entered design education, as well as neighbouring disciplines, such as business and IT. Design thinking makes use of designers' methods and tools to generate a better understanding of user needs in order to develop design innovations (Brown, 2008). Although the ideas behind design thinking can be compared to systematic design processes that have been defined already in the 1960s (Archer, 1965), the term was first introduced by Peter Rowe in 1984 (Rowe, 1984) and further defined later in the 1990s by design firm IDEO and its founder Tim Brown. According to Brown (2009) design thinking is based on three main pillars: (1) the aim for radical, disruptive innovation, (2) a user-centred approach, and (3) problem-solving through a systemic view on design beyond the mere product. This approach has influenced most of today's design thinking activities and will also guide our own investigation.

This view reflects the business and management perspective of design thinking and needs to be distinguished from the various research activities around design thinking, which originated in the early 1990s as a series of Design Thinking Research Symposia (DTRS). The first DTRS conference was held at Delft University of Technology in the Netherlands in 1991 (Cross, 2018). In contrast to the practical application of design thinking that aimed at solving business-related problems, design thinking research focused on studying designerly activities, methods, and ways of thinking in general. The education of design thinking principles can be traced back to 1967 when Stanford University founded the ME310 course - an academic engineering design course in which student teams worked on complex engineering design problems sponsored by industry partners (Carleton and Leifer, 2009). Later in 1984, the Center for Design Research (CDR) was established, which focused on engineering design innovation and design education (Stanford University, n.d.). Although it can be argued that both institutions already applied some of the design thinking principles that are widely established today, the term "design thinking" was introduced only later in 2005, when the first "School of Design Thinking" (short D-School) was founded at the Hasso Plattner Institute (HPI) in Stanford. The founding of the D-School was mainly initiated by Hasso Plattner, CEO of global software company SAP, who was introduced to and intrigued by the user-centred design approach by design firm IDEO.

The Stanford D-School was later complemented by a second institution - the D-School in Potsdam, Germany in 2007. For the remainder of the paper, we refer to the term "D-School", to describe the two HPI Schools of Design Thinking, because they are considered representative for a typical design thinking educational institution. For example, the design thinking at the University of St. Gallen is described to be influenced by the HPI D-Schools (Brenner et al., 2016). Today, design thinking education for students and professionals is very successful, and universities are increasingly implementing design thinking courses into their curricula (Wrigley and Straker, 2017). 


\section{Methodological approach}

This essay presents a theoretical comparison of the historic Bauhaus design education and contemporary design thinking education. We pursued a comparative multi-case study approach (Yin, 2003) in order to gain in-depth insights on both concepts. According to Yin, a single case study is appropriate when (a) the case is a "critical case", (b) when the case is extreme or unique, (c) when the case is representative or typical, and (d) when the case is revelatory in terms that the researcher has the unique opportunity to access and study it. We argue that the Bauhaus is a unique case in that sense that it existed only once. The D-School is considered a typical case, as outlined in the previous section. The comparison of the two individual case studies is what makes our study a multi-case study (Yin, 2003, p. 46). Our findings are extracted from a cross-case analysis between both cases.

Two of this paper's authors each have more than five years of experience in teaching design thinking at the D-School in Potsdam, which allowed them deep access to the entire teaching environment as well as the possibility to experience teaching practices first hand. In addition to this, two of this paper's authors work at a design school in Dessau, Germany, for more than ten years. The design school is located within direct neighbourhood to the historic Bauhaus building. Like most design schools it sees itself in the tradition of the historic Bauhaus school and works in close collaboration with the Bauhaus Dessau Foundation. Both facts led to deep access to both teaching concepts and hence provide the unique opportunity to gain rich insights into both institutions. Insights for the Bauhaus educational model were collected through (1) personal discussions with experts from the Bauhaus Foundation, (2) access to archived documents (photographs, teaching materials, etc.), and (3) additional literature search. Insights for the design thinking educational model were collected through (1) personal discussions with (former and current) teachers, students, and employees of the D-School, (2) observations of current environments and practices at the D-School, (3) access to archived documents (photographs, teaching materials, etc.) from the D-School, and (4) additional literature search.

The four authors of this paper reviewed the collected materials and mutually discussed their insights. Through this procedure, six categories of interest emerged inductively from the source materials: (1) curriculum, (2) multi-disciplinarity, (3) mind-set and culture, (4) study environment, (5) conditions for innovation, and (6) socio-economic context. Through cross-analysis between the two cases, several similarities and differences could be identified that are discussed in the following sections.

\section{Comparison of Bauhaus and design thinking education}

Both educational concepts, the Bauhaus school and design thinking education from the D-School example, provide teaching principles and positions that resemble strong beliefs and convictions of how design ought to be, The following subsections describe both concepts according to the six identified categories of interest: (1) curriculum, (2) multi-disciplinarity, (3) mind-set and culture, (4) study environment, (5) conditions for innovation, and (6) socio-economic context. Where applicable, we provide references to related literature.

\subsection{Curriculum}

The original Bauhaus' curriculum was organized in three consecutive steps. The first half year was dedicated to the so called "Vorkurs" (preliminary course) in which all the students experimented in different media and with different materials and were taught elementary foundations of form theory. After that, students explored one of the different workshops (metal, wood, photography, sculpture, ceramics, glass, graphic, stagecraft, printing, or weaving) that were led by individual teachers. Here, students developed various design artefacts that have later been partly offered for sale. Some of these designs became the artefacts known today as "design classics". The final step of the curriculum was supposed to be the "Baulehre" (architectural building) where all the previously acquired skills would be combined. The curriculum was pictured as a set of three concentric circles. This model worked in theory, but the steps were not followed strictly. Photography was introduced only in 1929 and the Baulehre only became reality in 1927 when Hannes Meyer was appointed to teach at the Bauhaus. Gropius had tried to establish the Baulehre already in Weimar but met resistance by the authorities 
which in part may have to do with the fact that students left the Bauhaus as journeymen and not as university graduates. Sculpture, ceramics and glass were only offered in Weimar. Stage design was cancelled in 1929 shortly before Ludwig Mies van der Rohe became director of the Bauhaus in 1930. Mies van der Rohe changed the structure of the offered courses by combining all workshops to one that would work entirely for the architecture department. Basically, it can be said that the Weimar period was still very much influenced by the arts and crafts movement which is reflected in the craftbased classes offered. The Dessau period focussed much more on production and on the systematic approaches to improve the living and working standards for all.

Curricular structures in design thinking cannot be easily identified, because they may differ among different institutions. For our comparison, we focus on the D-School in Potsdam, because it was among the first educational institutions for design thinking and was later often copied by other institutions. Moreover, we had deep access to this institution. Design thinking, as taught at the DSchool, is focused on project work and "learning by doing". External project partners from industry bring in their project briefings that are then worked by the student teams. Besides regular inputs from teachers there are no classes as such. The programme is designed as a further education. Students participate in the courses for two days per week, while still being enrolled in their respective major at another university. There is also an additional "pro track" targeted at people who already have a degree and some professional experience. Under the third director Mies van der Rohe, the Bauhaus was primarily attended by students who already had other degrees and therefore the Bauhaus became a "university for the second degree". This situation is similar to many design thinking programmes, that are typically offered as individual modules within other programmes (e.g. as part of a business degree), or — as is the case with the D-School in Potsdam — as some sort of further education.

\subsection{Multi-disciplinarity}

At the Bauhaus, different design disciplines were taught to the students, ranging from the different artistic disciplines, architecture, product and furniture design, graphic and typography to photography, filmmaking and theatre. However, after having completed the "Vorkurs", most students were studying in reality only one workshop. Hence the offer was multi-disciplinary but the education for each student was rather directed at one skill. Under the second Bauhaus director Hannes Meyer, the curriculum was enriched by other scientific classes, such as engineering, psychology, and sociology. Students were supposed to explore all these different areas during the "Vorkurs". Hence, multidiscplinarity was inherent in each individual student. The only workshop where all these disciplines were integrated and applied, was the stagecraft workshop. Here, students from all departments worked together to create a holistic show, involving, for example, wood and metal work, costume and textile design, graphics and typography, as well as music and performing arts.

Also, the teachers resembled the multi-disciplinary idea of the Bauhaus: Gropius designed buildings, furniture, wallpapers, objects for mass production, automobile bodies and even a diesel locomotive. László Moholy-Nagy was a painter, photographer, typographer, and stage designer, famous for his film and light experiments. He also published a series of Bauhaus books, and he had his own studio for typography, exhibition design, photomontage, and photo collage. Team-teaching was performed at the early Bauhaus in Weimar, in the way that "Formmeister" (the artists) and "Werkmeister" (the craftsmen) were teaching together.

At the D-School, multi-disciplinarity becomes manifest in design teams. Experts from different backgrounds work together and bring in their individual and unique expertise. One of the main concepts of design thinking is the idea that true innovation can only emerge from multi-disciplinary team work.

Team-teaching at the D-School follows the concept of "teams teaching teams". Ideally, also here different disciplines are combined in the teaching team to teach different expertise to the student teams.

\subsection{Mind-set and culture}

At both, Bauhaus and the D-School, we can see is the motivation to change the world, and a strong belief in technological advancement. The credo "new is better" and the underlying aim for innovation can be found at both educational contexts. At the D-School, this credo was regarded in terms of bigger, societal problems. Gropius founded the Bauhaus to improve the living and working processes as a whole and to 
spread democracy among the post-first-world-war society. These goals were to be accomplished by offering designs that are directed at everyone rather at an economical elite by employing technical advances and mass production. Hannes Meyer focused more on societal improvements and also aspects of natural sciences for example by introducing a structured analysis of light and sun to architectural planning.

Both have the mind-set of the designer (as opposed to that of e.g. a philosopher), which puts an emphasis on doing, trying, making something, rather than just talking and thinking about it. They see the designer's main task in solving big challenges and creating a better world.

At the D-School, so called "warm-ups" are performed several times during the day, in between different process steps. The range of exercise spans from sportive activities to improvisation games. The main goals of these exercises are to create a fun and playful atmosphere in order to loosen up, get rid of a fear to fail, and to improve group dynamics. As a consequence, the warm-ups were believed to increase creativity. Sometimes, the warm-ups were related to the respective process step (e.g. singing and breathing exercises before a presentation).

Although not called "warm-up", there is a similar activity at the Bauhaus in Weimar: introduced by Gertrud Grunow as "Harmonisation Theory", exercises included body-movement, breathing exercises, and dancing. The goal was mainly to enhance creativity but also to promote and protect health. This was in response to the life reform movement that had started in the mid $19^{\text {th }}$ century in Germany and Austria. Though later in Dessau, such reform classes were not part of the regular schedule, the students did engage in gymnastics, preferably on the roof of the student dormitory, and also played soccer on the large grass area next to the cafeteria, as photographs of the time show. Moreover, from 1926 onwards, Oskar Schlemmer introduced the Bauhaus dances on the Bauhaus stage in Dessau, including, for example, "space dance" and "gesture dance" (Bauhaus Cooperation, 2019), which also reflects the attempt to explore bodily movements in unison with stage elements.

Bauhaus and Design Thinking, both have resemblance with a big family (one might also say "fraternity" or even a "cult"). Both had the idea of a strong community. At the Bauhaus, Walter Gropius acted as a sort of father figure. Later, in Dessau, Hannes Meyer promoted a more democratic study atmosphere with flat hierarchies. Students and some of the younger teachers lived in the student dormitory in Dessau. Teachers and students also spent time together at the cafeteria and occasionally Schlemmer, Klee, Kandinsky, and Feininger invited students to their private homes. Friendships between students and teachers emerged and also families were founded. Interesting is the teacherstudent relationship: students were called apprentices and teachers were masters. This led to low hierarchies and benefited the general atmosphere.

Also, there is a bit of an eccentric, experimental attitude (Bauhäuslers thought of themselves as Bohemian, avant-gardist pioneers, and the Design Thinkers see themselves as innovative, cutting-edge pioneers), which is sometimes even a bit ridiculed from outsiders, in both cases.

At both, Bauhaus and D-School selected graduate students became teachers. At the Bauhaus, alumni students were appointed as junior masters ("Jungmeister"). At the D-School in Potsdam, the majority of teachers are former students.

Another similarity for both institutions (Bauhaus and D-School) is the absence of grades. Students could only pass (or seldomly fail) the classes. This approach supports the concept of an experimental approach to design and problem-solving. The strive for innovation should be motivated intrinsically, rather than inflicted by external incentives.

\subsection{Study environment}

If one compares the study environment at the Bauhaus to the more conventional and traditional architecture school and art academies at the time, it becomes evident that skill, motivation, and enthusiasm were highly valued. Hierarchy and personal distance were not the dominant teaching style. Instead, it was a project of togetherness and cooperation, which resulted in radically new concepts of how to design the world and its objects. Similarly, the study environment at the D-School focused on low hierarchies, teamwork, and togetherness, as well as on stimulating creativity. These attempts were also reflected in the design of the physical environments at both institutions.

When Walter Gropius designed the new building for the avant-garde design school - the Bauhaus - in Dessau, Germany, in 1926, he tried to create architecture that would facilitate the design students' 
creative activities (MacCarthy, 2019, p. 176). Large windows provided plenty of light and scenic views (Siebenbrodt and Schöbe, 2012, p. 194). Those large windows made the Bauhaus look like a factory made of glass allowing for the students to never lose contact with the space and nature around them and for the bystanders to have a glimpse at what was going on behind normally closed walls. It was a laboratory of light, space, air, and sun. Another innovative aspect of the building was the integration of different spatial functions within one building (Siebenbrodt and Schöbe, 2012, p. 193). Each functional section was dedicated to its own architectural area. The "Werkstattflügel" (workshop wing) housed the workshops; the "Bridge" was dedicated to administrative offices, and the "Atelierhaus" (studio building) served as the students' dormitory. The "Meisterhäuser" (masters' houses), located nearby, were private accommodations for the Bauhaus "masters"- the professors. The proximity of the different areas contributed to the familiar atmosphere and overall feeling of togetherness.

In design thinking contexts, a focus is given on team spaces. Collaboration furniture, such as team booths separated by whiteboards, is widely implemented. Intermission spaces are also integrated into the work processes, for example in the form of fully equipped outdoor booths. Furniture is consistently on wheels to allow flexible spaces and switching in between usage scenarios. The interior is very colourful, toys and gadgets are available throughout the space, and communal areas invite for casual chats and evening parties. Also here, the physical workspace reduces hierarchies and creates a familiar atmosphere of togetherness. Both spatial concepts were based on the assumption that the physical workspace can have an impact on the creative process and increase the creativity of the students. A detailed investigation of the role of physical space on creative processes can be found in Thoring (2019).

\subsection{Conditions for innovation}

The typical design thinking conceptual model consists of three elements: viability (business), feasibility (technology), and desirability (human values) (Brown, 2009, p. 19) that should be met to define an innovation (Brown, 2008). The focus in design thinking is typically on the user values, and consequently, user research and testing are one of the main pillars of design thinking education. This approach is based on the belief that the main reason why products fail is because they do not address an actual user need (Liedtka, 2015).

The Bauhaus, however, emphasizes the unity of Art, Technology, and Life. The elements of "Art" at the Bauhaus were taught in the preliminary course and the first year (form theory, colour theory, painting, sculpting, etc.), and also the final product should present aesthetic qualities. The focus on the beauty of functional yet good-looking objects, without unnecessary decoration, was stronger in the Weimar era, whereas later in Dessau, the focus shifted towards scientific approaches and meeting user needs. Both, 'Life' and 'Human Values' can be interpreted as a user-centred approach. The D-School focuses on extensive user research as well as obtaining user feedback during testing, in order to identify latent user needs. The main question is if a product actually solves a real problem for the user. This is analogue to similar innovation processes like "lean startup" (Mueller and Thoring, 2012). Also, the Bauhaus is focusing on usability and propagates their designs to be 'made for the use', they seek to create high-quality and inexpensive products for the masses. And furthermore: they also claim to design a new way of life, the design of "life processes", as mentioned by Walter Gropius (Poerschke, 2016). Moreover, also the requirement of meeting the 'people's needs' was emphasized-a requirement introduced by the second director Hannes Meyer, who included questions of utility, economy, and social target group into the workshop activities (Droste, 2002, p. 196).

The D-School lacks the "Art" component. The actual "design" (shaping, development) of a solution is not so much the focus. Often the process ends with the concept. Instead, the D-School introduced the "Business" component to their core values. A solution should also be marketable and financially viable. The Bauhaus was not so much emphasizing the business component, although efficiency and the possibility to produce a product in a way that makes it affordable for the masses were highly important. At the Bauhaus, cooperation with industry became a vital part of the education (especially under the second director Hannes Meyer). A frequent sponsoring by Junkers aircraft manufacturer lead to raising critique and even to the leaving of Moholy-Nagy. At the D-School cooperation with industry and the involvement of real clients are one of the main pillars of the educational concept. 


\subsection{Socio-economic context}

After 1919, the Bauhaus evolved from a special socio-economic setting. The initial era in Weimar was influenced by the arts and crafts movement. In the Dessau era, design was determined by industrialization and technological and economic change that led to a high demand for numerous highquality but affordable products. Problems that the designers addressed were related to production techniques, materiality possibilities, as well as functionality and affordability for the users.

Throughout the 14 years of its existence, the Bauhaus was always publicly funded. Consequently, it was often affected by political and financial constraints. A consistent political position was difficult to achieve, due to the troubled times of the post-first-world-war era, preceding the upcoming takeover of the Nazis in 1933, which also marked the end of the Bauhaus. Especially under third director Ludwig Mies van der Rohe, the Bauhaus struggled to find a unified political position, but rather adapted to the changing political and industrial demands they were confronted with (Hochman, 1989).

By contrast, design thinking education at the D-School is privately funded, partly sponsored by its founder Hasso Plattner; partly financed through money from industry collaborations. This situation led to a rather market-driven educational approach. Today, design thinking reflects saturated markets (there is no actual need for more toothbrushes or chairs). As a result, the relevance of design shifts towards the identification of latent and previously unknown user needs. At the same time, there is an increased awareness of societal, environmental, and political problems. Such wicked problems (Rittel, 1972) are also tackled with design thinking. Today's technological advancements disrupt many business models (e.g. self-driving cars disrupt the automotive industry). As a reaction, CEOs desperately seek for innovative remedies and therefore are open to design thinking's promises, which partly explains the ongoing success of design thinking approaches.

\section{Discussion}

\subsection{Summary}

Although both, the historic Bauhaus and contemporary design thinking education, are separated by almost a century, it is surprising how many similarities can be found. Table 1 summarizes the identified differences and similarities between the Bauhaus and contemporary design thinking education.

Table 1. Overview of main differences and similarities of the Bauhaus and design thinking

\begin{tabular}{|l|l|l|}
\hline & Bauhaus & Design Thinking Education \\
\hline Curriculum & - Multi-disciplinary Vorkurs for all & - Basic Track followed by Advanced Track \\
& - Selection from different workshops, led & (increased complexity) \\
& by different teachers & - Focus on project-based learning \\
& - Focus on disciplinary workshops & - Regular lectures from teachers to \\
& - Main goal is "Baulehre" (architectural & everybody \\
& building) & - Main goal is innovation \\
& - Further education (introduced by $3^{\text {rd }}$ & - Further education (in addition to other \\
& director), students had prior work & major), students partly have prior work \\
& experience & - Within teams \\
\hline Multi- & - Within students & - Team-teaching \\
Disciplinarity & - Tandem-teaching & - No grades \\
\hline Mindset and & - No grades & - Warm-ups to increase creativity \\
Culture & - Health focus, breathing exercises & - Regular parties \\
& - Regular parties & - Students become teachers \\
& - Students become teachers & - Familiar atmosphere, friendships \\
& - Familiar atmosphere, friendships & - Experimentation and making \\
& - Experimentation and making & - Slightly eccentric attitude \\
\hline
\end{tabular}




\begin{tabular}{|c|c|c|}
\hline & Bauhaus & Design Thinking Education \\
\hline $\begin{array}{l}\text { Study } \\
\text { Environment }\end{array}$ & $\begin{array}{l}\text { - Open ateliers } \\
\text { - Laboratory of light, space, air, sun } \\
\text { - Should support creativity } \\
\text { - Proximity of teachers and students }\end{array}$ & $\begin{array}{l}\text { - Open structures, no dividing walls } \\
\text { - Includes outdoor areas } \\
\text { - Should support creativity } \\
\text { - Support flat hierarchies }\end{array}$ \\
\hline $\begin{array}{l}\text { Conditions } \\
\text { for } \\
\text { Innovation }\end{array}$ & $\begin{array}{l}\text { - Aim for radical innovation } \\
\text { - Aim to improve the world } \\
\text { - Targeting social and industry problems } \\
\text { - Unity of art, technology, and life }\end{array}$ & $\begin{array}{l}\text { - Aim for radical innovation } \\
\text { - Aim to improve the world } \\
\text { - Targeting bigger societal (“wicked") } \\
\text { problems } \\
\text { - Unity of viability, feasibility, and } \\
\text { desirability, focus on user needs } \\
\end{array}$ \\
\hline $\begin{array}{l}\text { Socio- } \\
\text { Economic } \\
\text { Context }\end{array}$ & $\begin{array}{l}\text { - Publicly funded and hence affected by } \\
\text { political environment } \\
\text { - Determined by economic scarcity } \\
\text { - Goal to change the world }\end{array}$ & $\begin{array}{l}\text { - Privately funded; not affected by politics } \\
\text { - Determined by saturated markets } \\
\text { - Technological advancements disrupt } \\
\text { traditional business models } \\
\text { - Goal to change the world }\end{array}$ \\
\hline
\end{tabular}

When comparing both approaches, the similarities are striking. Both educational concepts were somewhat different than the respective status quo and both questioned the design educational standards that were prevalent hitherto. Both aimed at innovation and radical change; both pursued user-centred approaches; both had peculiar study environments; both propagated a specific mind-set and culture that can be viewed as a big family or even a cult; and both involved multi-disciplinary approaches.

\subsection{Implications for today's design education}

Under directors Gropius and Meyer, the Bauhaus has always worked for the greater goal of improving living and working conditions for the society as a whole. The different kinds of building concepts that were realized demonstrate this goal. The "Törten Housing Estate", developed by Walter Gropius, provided affordable houses including gardens for planting fruits and vegetables. Similarly, the balcony access houses by Hannes Meyer (also in Törten) offered three-room apartments including a bathroom and kitchen on only 48 sqm, which were meant to help with the lack of available housing at that time. We argue, though, that the challenges today have become wicked, more systemic, and interdisciplinary. 100 years ago, design was determined by scarcity, whereas today, design thinking tackles bigger challenges and "wicked problems" that go beyond the traditional understanding of the design discipline and also affect neighbouring disciplines. As a consequence, design thinking can be seen on a larger scale with a wider scope, which is reflecting today's social problems. The increased complexity of the world today requires more individual experts from different disciplines, who work together as a team rather than multi-disciplinary individuals. Design thinking propagates exactly this kind of multi-disciplinary teamwork that could result in solving such challenges.

The "Vorkurs" of the Bauhaus prepared the design students for the subsequent requirements of the complex and multidisciplinary design projects within the study programme. By contrast, the design thinking education (as taught at the D-School) prepares students from all disciplines for the greater challenges of today's societal problems. In that sense, design thinking education provides people across all disciplines with the skillset and mind-set to tackle such grand challenges. Students who graduate from design thinking education continue to work in larger corporations and introduce their acquired design thinking skills to society. Consequently, we consider design thinking as the preparatory course for the $21^{\text {st }}$ century.

\subsection{Limitations}

This paper is not aiming to provide an in-depth description and analysis of either of the two schools, and hence does not claim completeness. Such investigations are beyond the scope of this paper. Detailed descriptions and analyses of design thinking are provided by several authors (Brenner et al., 2016; Brown, 2009; Liedtka, 2013; Martin, 2009). A critical take on design thinking can be found, for example, in Badke-Schaub et al. (2010). For more information on the Bauhaus school we refer the 
readers to existing work on the history and the educational model of the Bauhaus (Chen and He, 2013; Donoso et al., 2018; Droste, 2002; Siebenbrodt and Schöbe, 2012). Instead, with this paper we focus on specific aspects of both educational schools that allowed the juxtaposition of concepts and through comparison allowed us to propose assumptions on possible underlying aims and impacts of particular rituals, methods, and environments.

Another limitation of this study is the fact that neither the Bauhaus nor design thinking education can be subsumed under one standardized teaching concept. The Bauhaus approach differed significantly among the three directors (Walter Gropius, Hannes Meyer, and Ludwig Mies van der Rohe), as well as among the three locations (Weimar, Dessau, and Berlin). Therefore, some of the mentioned characteristics were not generally valid for the entire Bauhaus, but rather addressed specific episodes of the different phases. The same limitation applies for design thinking education. The D-School in Potsdam differs slightly from the D-School in Stanford (mainly in terms of the curriculum), and both differ from other educational design thinking programmes that have been established later-on. Consequently, this study cannot be generalized to design thinking education in general, but focuses on a single case in one particular institution, only (the D-School in Potsdam). For the same reason, we did not include a discussion of the "design process" for both approaches into our comparison. The design thinking process is quite consistent within the D-School and also in other institutions that apply design thinking, which mainly follow the process suggested by Brown $(2008,2009)$. A detailed description of the design thinking process at the D-School can be found, for example, in Thoring and Mueller (2011). The Bauhaus, however, cannot be easily reduced to one particular process. Instead, every Bauhaus teacher followed their own process and methods. Therefore, we saw no merit in comparing the respective design processes. Nevertheless, we argue that the presented insights contribute to a general understanding of differences and similarities of both design educational approaches, and hence, warrant our attempt to speculate about their respective societal impact.

\section{Conclusions}

This paper presents a comparison of the design educational concepts of the Bauhaus school (19191933) and contemporary design thinking education. To answer our Research Question 1, we explored differences and similarities of both institutions based on observations, personal discussions with students, teachers, and experts, archived documents, and related literature. The resulting insights are summarized in a conceptual framework. Our Research Question 2 asked what the collected insights could tell us about design education, today. We answered this question by presenting speculative thoughts about the possible impact of both concepts on the society of each time, as well as their respective influence for the future of design education. The insights presented in this paper might contribute to a better understanding of educational strategies, mind-sets, spaces, and philosophies for the goal to tackle current societal challenges.

\section{References}

Archer, L.B. (1965), Systematic Method for Designers, Council of Industrial Design (UK), London.

Badke-Schaub, P., Roozenburg, N. and Cardoso, C. (2010), "Design thinking: a paradigm on its way from dilution to meaninglessness", Proceedings of the 8th Design Thinking Research Symposium, pp. 19-20.

Bauhaus Cooperation (2019), "Classes by Oskar Schlemmer", Bauhaus100, available at: https://www.bauhaus 100.com/the-bauhaus/training/curriculum/classes-by-oskar-schlemmer/ (accessed 18 November 2019).

Brenner, W., Uebernickel, F. and Abrell, T. (2016), "Design Thinking as Mindset, Process, and Toolbox", In: Brenner, W. and Uebernickel, F. (Eds.), Design Thinking for Innovation: Research and Practice, Springer International Publishing, Cham, pp. 3-21.

Brown, T. (2008), "Design Thinking”, Harvard Business Review, Vol. 86 No. 6, pp. 84-92.

Brown, T. (2009), Change by Design: How Design Thinking Transforms Organizations and Inspires Innovation, Harper Business, New York.

Carleton, T. and Leifer, L. (2009), "Stanford's ME310 Course as an Evolution of Engineering Design”, In: Roy, R. and Shehab, E. (Eds.), Proceedings of the 19th CIRP Design Conference-Competitive Design.

Chen, W. and He, Z. (2013), "The Analysis of the Influence and Inspiration of the Bauhaus on Contemporary Design and Education”, Engineering, Vol. 5 No. 04, p. 323. 
Cross, N. (2018), “A brief history of the Design Thinking Research Symposium series”, Design Studies, Vol. 57, pp. 160-164.

Donoso, S., Mirauda, P. and Jacob, R. (2018), "Some ideological considerations in the Bauhaus for the development of didactic activities: The influence of the Montessori method, the modernism and the gothic", Thinking Skills and Creativity, Vol. 27, pp. 167-176.

Dorst, K. (2015), "Frame Creation and Design in the Expanded Field", She Ji: The Journal of Design, Economics, and Innovation, Vol. 1 No. 1, pp. 22-33.

Droste, M. (2002), Bauhaus: 1919-1933, Taschen, Köln.

Findeli, A. (2001), "Rethinking design education for the 21st century: Theoretical, methodological, and ethical discussion", Design Issues, Vol. 17 No. 1, pp. 5-17.

Hochman, E. (1989), Architects of Fortune: Mies van Der Rohe and the Third Reich., 1, Weidenfeld \& Nicolson, New York.

Junginger, S. (2013), "Design and Innovation in the Public Sector: Matters of Design in Policy-Making and Policy Implementation", Annual Review of Policy Design, Vol. 1 No. 1, pp. 1-11.

Liedtka, J. (2013), "Design Thinking: What it is and Why it Works", Vol. 96 No. 5, pp. $72-79$.

Liedtka, J. (2015), "Perspective: Linking Design Thinking with Innovation Outcomes through Cognitive Bias Reduction”, Journal of Product Innovation Management, Vol. 32 No. 6, pp. 925-938.

MacCarthy, F. (2019), Gropius: The Man Who Built the Bauhaus, The Belknap Press of Harvard University Press, Cambridge.

Martin, R. (2009), The Design of Business: Why Design Thinking Is the next Competitive Advantage, Harvard Business Press, Boston, Mass.

Mueller, R.M. and Thoring, K. (2012), "Design Thinking vs. Lean Startup: A Comparison of two User-Driven Innovation Strategies", Leading Innovation through Design: Proceedings of the DMI 2012 International Research Conference, presented at the DMI, Design Management Institute, Boston, USA, pp. 151-161.

Orlandi, A.E.C. (2010), "Experimental experience in design education as a resource for innovative thinking: The case of Bruno Munari", Procedia - Social and Behavioral Sciences, Vol. 2 No. 2, pp. 5039-5044.

Poerschke, U. (2016), Architectural Theory of Modernism: Relating Functions and Forms, Routledge, New York.

Rittel, H. (1972), "On the planning crisis: Systems analysis of the first and second generations", Bedriftskonomen, Vol. 8, pp. 390-396.

Rowe, P.G. (1984), Design Thinking, MIT Press, Cambridge, Mass. London.

Siebenbrodt, M. and Schöbe, L. (2012), Bauhaus: 1919-1933, Weimar-Dessau-Berlin, Parkstone International, New York, available at: (accessed 7 July 2019).

Stanford University. (n.d), "The Center for Design Research", available at: https://me.stanford.edu/research/labsand-centers/center-design-research/center-design-research (accessed 8 February 2020).

Thoring, K. (2019), Designing Creative Space, Ph.D. Thesis, Delft University of Technology, Delft, The Netherlands.

Thoring, K. and Müller, R.M. (2011), "Understanding Design Thinking: A Process Model based on Method Engineering", Proceedings of the 13th International Conference on Engineering and Product Design Education (E\&PDE), London, UK.

Vogel, C.M. (2009), "Notes on the evolution of design thinking: A work in progress", Design Management Review, Vol. 20 No. 2, pp. 16-27.

Wilhelm, K. and Gropius, W. (1983), Walter Gropius, Industriearchitekt, F. Vieweg, Braunschweig.

Wrigley, C. and Straker, K. (2017), "Design Thinking pedagogy: the Educational Design Ladder", Innovations in Education and Teaching International, Vol. 54 No. 4, pp. 374-385.

Yin, R.K. (2003), Case Study Research: Design and Methods, Sage Publications, Thousand Oaks. 